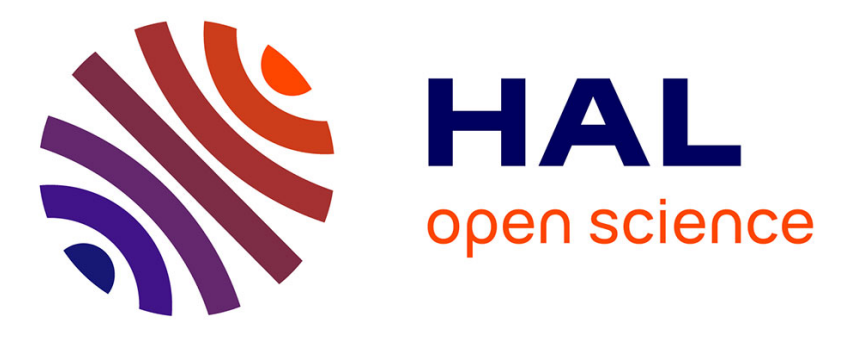

\title{
Semi-empirical calculation of electronic absorption wavelengths of polyynes, monocyano- and dicyanopolyynes. Predictions for long chain compounds and carbon allotrope carbyne \\ Anthony Scemama, Patrick Chaquin, Marie-Claire Gazeau, Yves Bénilan
}

\section{To cite this version:}

Anthony Scemama, Patrick Chaquin, Marie-Claire Gazeau, Yves Bénilan. Semi-empirical calculation of electronic absorption wavelengths of polyynes, monocyano- and dicyanopolyynes. Predictions for long chain compounds and carbon allotrope carbyne. Chemical Physics Letters, 2002, 361 (5-6), pp.520-524. 10.1016/S0009-2614(02)00988-0 . hal-01539078

\author{
HAL Id: hal-01539078 \\ https://hal.science/hal-01539078
}

Submitted on 28 Jan 2020

HAL is a multi-disciplinary open access archive for the deposit and dissemination of scientific research documents, whether they are published or not. The documents may come from teaching and research institutions in France or abroad, or from public or private research centers.
L'archive ouverte pluridisciplinaire HAL, est destinée au dépôt et à la diffusion de documents scientifiques de niveau recherche, publiés ou non, émanant des établissements d'enseignement et de recherche français ou étrangers, des laboratoires publics ou privés. 


\title{
Semi-empirical calculation of electronic absorption wavelengths of polyynes, monocyano- and dicyanopolyynes. Predictions for long chain compounds and carbon allotrope carbyne
}

\author{
Anthony Scemama ${ }^{\mathrm{a}}$, Patrick Chaquin ${ }^{\mathrm{a}, 1}$, Marie-Claire Gazeau ${ }^{\mathrm{b}}$ \\ and Yves Bénilan ${ }^{b}$ \\ ${ }^{a}$ Laboratoire de Chimie Théorique, UMR 7616 du CNRS, Université Pierre et \\ Marie Curie Paris VI, Case 137, 4, place Jussieu 75252 PARIS CEDEX 05, \\ France \\ ${ }^{\mathrm{b}}$ Laboratoire Interuniversitaire des Systèmes Atmosphériques, UMR 7583 du \\ CNRS, Universités Paris VII \& Paris XII, 94010 Créteil Cedex, France
}

\begin{abstract}
Absorption wavelengths and oscillators strengths have been calculated for the allowed low-energy electronic transition ${ }^{1} \Sigma^{+} \leftarrow^{1} \Sigma^{+}$of monocyanopolyynes $\left(\mathrm{HC}_{y} \mathrm{~N}\right.$, $y=1-13),{ }^{1} \Sigma_{u}^{+} \leftarrow{ }^{1} \Sigma_{g}^{+}$of polyynes and dicyanopolyynes $\left(\mathrm{HC}_{y} \mathrm{H}\right.$ and $\mathrm{NC}_{y} \mathrm{~N}$, $y=1-40)$. For $y>18$, the geometries were extrapolated from DFT optimization of the shortest members. Extrapolation formulas have been drawn up for longer chains, the asymptotic values of those yield an estimation of the absorption wavelength $(c a .400 \mathrm{~nm})$ of the hypothetical carbon allotrope carbyne.
\end{abstract}

Key words: polyyne, monocyanopolyyne, dicyanopolyyne, UV

\section{Introduction}

Except their first members, polyynes $\mathrm{H}(\mathrm{C} \equiv \mathrm{C})_{n} \mathrm{H}$, monocyanopolyynes $\mathrm{H}(\mathrm{C} \equiv$ $\mathrm{C})_{n} \mathrm{CN}$ and dicyanopolyynes $\mathrm{NC}(\mathrm{C} \equiv \mathrm{C})_{n} \mathrm{CN}$ are highly reactive under terrestrial conditions and thus are very difficult to synthesize. Nevertheless, polyynes have been obtained up to $n=5$ in solution or gas phase[1] and to $n=12$

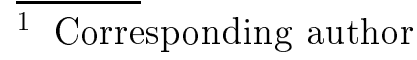

Preprint submitted to Elsevier Science

10 April 2002 
in neon matrixes[2], and a synthesis and spectroscopic characterization of dicyanopolyynes $(n=2-8)$ have been published[22]. On the other hand, monocyano compounds have been detected since the 70's [3-6] in interstellar clouds ; the other two series should also be present since the derived radicals $\mathrm{C}_{x} \mathrm{H}$ and $\mathrm{C}_{x} \mathrm{~N}$ have been detected[7-10]. The atmosphere of Titan, mainly composed of $\mathrm{H}, \mathrm{C}$ and $\mathrm{N}$ elements contains polyynes already characterized. Photochemically reactive in the UV range, these compounds constitute precursors to the visible absorbing haze materials present in Titan and many of the outer planets atmospherex [11](and references therein). In addition, as recently recalled by Hirsch et al.[12], long polyynes are model units of the hypothetical dicoordinated carbon allotrope "carbyne" $-(\mathrm{C} \equiv \mathrm{C})_{\infty}-$.

Beside IR frequencies, UV data are an alternative way for the detection and determination the concentration of long polyynes, especially thanks to their low energy allowed transition, ${ }^{1} \Sigma_{u}^{+} \leftarrow{ }^{1} \Sigma_{g}^{+}$in $\mathrm{D}_{\infty h}$ polyynes and dicyanopolyynes, ${ }^{1} \Sigma^{+} \leftarrow{ }^{1} \Sigma^{+}$in $\mathrm{C}_{\infty v}$ monocyanopolyynes. We present here semi-empirical calculations of the energy of these transition up to $\mathrm{C}_{40} \mathrm{H}_{2}, \mathrm{C}_{40} \mathrm{~N}_{2}$ and $\mathrm{HC}_{13} \mathrm{~N}$, and an evaluation of the HOMO-LUMO gap in infinite chain compounds.

\section{Calculation Methods}

The Gaussian98 series of programs[13] has been used throughout this work. The energy of electronic transition and the corresponding oscillator strengths have been obtained using the ZINDO method[14]. The geometrical parameters have been obtained by two different ways, as detailed in a previous paper[15]. For the shortest compounds up to $\mathrm{C}_{16} \mathrm{H}_{2}, \mathrm{C}_{16} \mathrm{~N}_{2}$ and $\mathrm{C}_{13} \mathrm{HN}$, the geometry was optimized at the B3LYP[16,17] level with Dunning's triple zeta basis set (cc-pVTZ)[18]. From these data and additional calculation of the geometries of $\mathrm{C}_{30} \mathrm{H}_{2}$ and $\mathrm{C}_{30} \mathrm{~N}_{2}$, extrapolation formulas were stated for both centrosymmetric series. As a final result, in $\mathrm{C}_{y} \mathrm{H}_{2}$ the length of the $x^{\text {th }} \mathrm{C} \equiv \mathrm{C}$ bond is given by

$$
d(x, y)=1.2289-0.06294 e^{-0.2318 y}-0.1041 e^{-0.3613 y}|x-0.5+0.25 y|^{1.7+0.1 y}
$$

and the length of the $x^{\text {th }} \mathrm{C}-\mathrm{C}$ bond is given by

$$
d^{\prime}(x, y)=1.3290+0.1096 e^{-0.2401 y}+0.2169 e^{-0.3634 y}|x-0.25 y|^{1.6+0.098 y}
$$

In the $\mathrm{C}_{y} \mathrm{~N}_{2}$ series the corresponding formulas are, for the $x^{\text {th }} \mathrm{C} \equiv \mathrm{C}$ bond

$$
d(x, y)=1.2281-0.1112 e^{-0.2947 y}-0.1159 e^{-0.3614 y}|x-0.25 y|^{1.6+0.1 y}
$$


and for the $x^{\text {th }} \mathrm{C}-\mathrm{C}$

$$
d^{\prime}(x, y)=1.3295+0.1442 e^{-0.3071 y}+0.2685 e^{-0.4301 y}|x-0.5+0.25 y|^{2.0+0.115 y}
$$

This way, vertical transition energies with equilibrium geometry of the ground state are obtained. We can assume that the equilibrium geometry of the excited state is close to that of the ground state, especially for longer chains. As a matter of fact, the experimental spectra exhibit a strong $0 \rightarrow 0$ component, and thus the calculated wavelengths can be compared those experimental observed for this transition.

\section{Results and discussion}

\section{$3.1 C_{\infty v}$ series of monocyano polyynes}

The calculated and experimental wavelengths, and the calculated oscillator strengths are given in table 1. Because accurate extrapolation formulas for the geometrical parameters could not be obtained in this series, we report only results from $\mathrm{HCN}$ to $\mathrm{HC}_{13} \mathrm{~N}$. Moreover, due to the high toxicity and reactivity of these compounds, very few experimental data are available, nevertheless in good agreement with the calculated ones. An extrapolation formula for $\lambda$ (nm) can be proposed :

$$
\lambda\left(\mathrm{HC}_{y} \mathrm{~N}\right)=95.167+320.532\left(1-e^{-0.058 y}\right)
$$

Accordingly, the absorbtion wavelength reaches a limit for $y$ infinite, which can be evaluated to $c a .416 \mathrm{~nm}$. The oscillator strength varies according to the fitted function

$$
f\left(\mathrm{HC}_{y} \mathrm{~N}\right)=2.26315+0.41820 y-2.8349 e^{-0.06064 y}
$$

the variation of which becomes rapidly linear as $y$ increases.

\section{2 $D_{\infty h}$ series of polyynes and dicyano polyynes}

In tables 2 and 3 we report calculated and experimental data for polyynes and dicyanopolyynes respectively. Two series of calculated values are displayed corresponding to both methods of determination of the geometrical parameters : from $\mathrm{C}_{2}$ to $\mathrm{C}_{18}$ and for $\mathrm{C}_{30}$ compounds we used the optimized geometry at the B3LYP/cc-pVTZ basis set level ; from $\mathrm{C}_{2}$ to $\mathrm{C}_{40}$ compounds we used the

extrapolation formulas given in the preceding section. For seek of clarity, the 
variation of $\lambda$ as a function of the number of carbon atoms is shown graphically in figures 1 and 2 respectively for polyynes and dicyanopolyynes.

Regarding the absorption wavelenghts, we first note that both calculation methods give results very close one another since they differ by less than 2 $\mathrm{nm}$ in the $\mathrm{C}_{2}-\mathrm{C}_{18}$ range and $6 \mathrm{~nm}$ for the $\mathrm{C}_{30}$ molecules, at any rate less than $1000 \mathrm{~cm}^{-1}$ in energy, which indicates the reliability of the extrapolation formulas. As compared to experimental results, we have to take into account the various physical states of the samples. Spectra of polyynes ranging from $\mathrm{C}_{2} \mathrm{H}_{2}$ to $\mathrm{C}_{8} \mathrm{H}_{2}$ were obtained in the gas phase whereas in the range $\mathrm{C}_{12} \mathrm{H}_{2}-\mathrm{C}_{24} \mathrm{H}_{2}$, they were obtained in a neon matrix, which is expected to be close to vacuum conditions. For all these compounds, the calculated values appear to be systematically overestimated by $c a$. $1000-2000 \mathrm{~cm}^{-1}$. This difference is indeed rather small and should be lesser after correction by the difference of ZPEs between the ground state and the excited state of concern. Larger discrepancies between experimental and calculated absorption wavelengths exhibited for other compounds can be partly due to experimental conditions. As a matter of fact, the UV spectrum of $\mathrm{C}_{10} \mathrm{H}_{2}$ has been recorded in methanol solution ; spectra of the dicyano series were recorded in acetonitrile solution. In the latter series, we note an energy error almost constant $c a .4000 \mathrm{~cm}^{-1}$. The following extrapolation formulas are proposed for wavelengths aborptions as a function of $y$, the number of carbon atoms :

$$
\begin{gathered}
\lambda\left(\mathrm{HC}_{y} \mathrm{H}\right)=66.9848+316.561\left(1-e^{-0.058 y}\right) \\
\lambda\left(\mathrm{HC}_{y} \mathrm{~N}\right)=96.0384+290.163\left(1-e^{-0.066160 y}\right)
\end{gathered}
$$

Like in the monocyano series the oscillators strengths tends toward a linearily increasing asymptote as the length of the molecule increases according to :

$$
\begin{aligned}
& f\left(\mathrm{HC}_{y} \mathrm{H}\right)=2.20467+0.41355 y-3.0823 e^{-0.16048 y} \\
& f\left(\mathrm{NC}_{y} \mathrm{~N}\right)=2.32163+0.42284 y-2.8349 e^{-0.25667 y}
\end{aligned}
$$

\section{Predictions for carbon allotrope carbyne}

Long chain polyynes can be regarded as models of infite linear carbon chains which constitute an hypothetical carbon allotrope. Previous calculations [19$23,15]$ at various levels indicate that an alternation of shorter "triple" bond and longer "single" bonds might persist in an infinite chain, resulting in a HOMOLUMO gap and insulator properties. As a good index of this gap, the asymptotic absorption wavelength $\lambda_{\infty}$ of polyynes, was evaluated to $565-570 \mathrm{~nm}$ by several experimentalists using various end-cap protected polyynes[?,12,22,26]. 
By extrapolation, values of $416 \mathrm{~nm}, 384 \mathrm{~nm}$ and $386 \mathrm{~nm}$ are found from formulas 5, 7 and 8 respectively. The mean value, ca. $400 \mathrm{~nm}$ is rather shorter than those previously published, indicating, if true, that the asymptotic value is reached more rapidly than expected by the preceding authors. Even after correction of $4000 \mathrm{~cm}^{-1}$ in energy, which appears as the maximum error of calculated values (in the dicyano series), a value of $c a .480 \mathrm{~nm}$ is found, which remains smaller than $565 \mathrm{~nm}$ by $3000 \mathrm{~cm}^{-1}$.

\section{Acknowledgements}

The authors gratefully acknowledge the CCR (Centre de Calcul Recherche et Réseau Jussieu) for the use of computing facilities. 


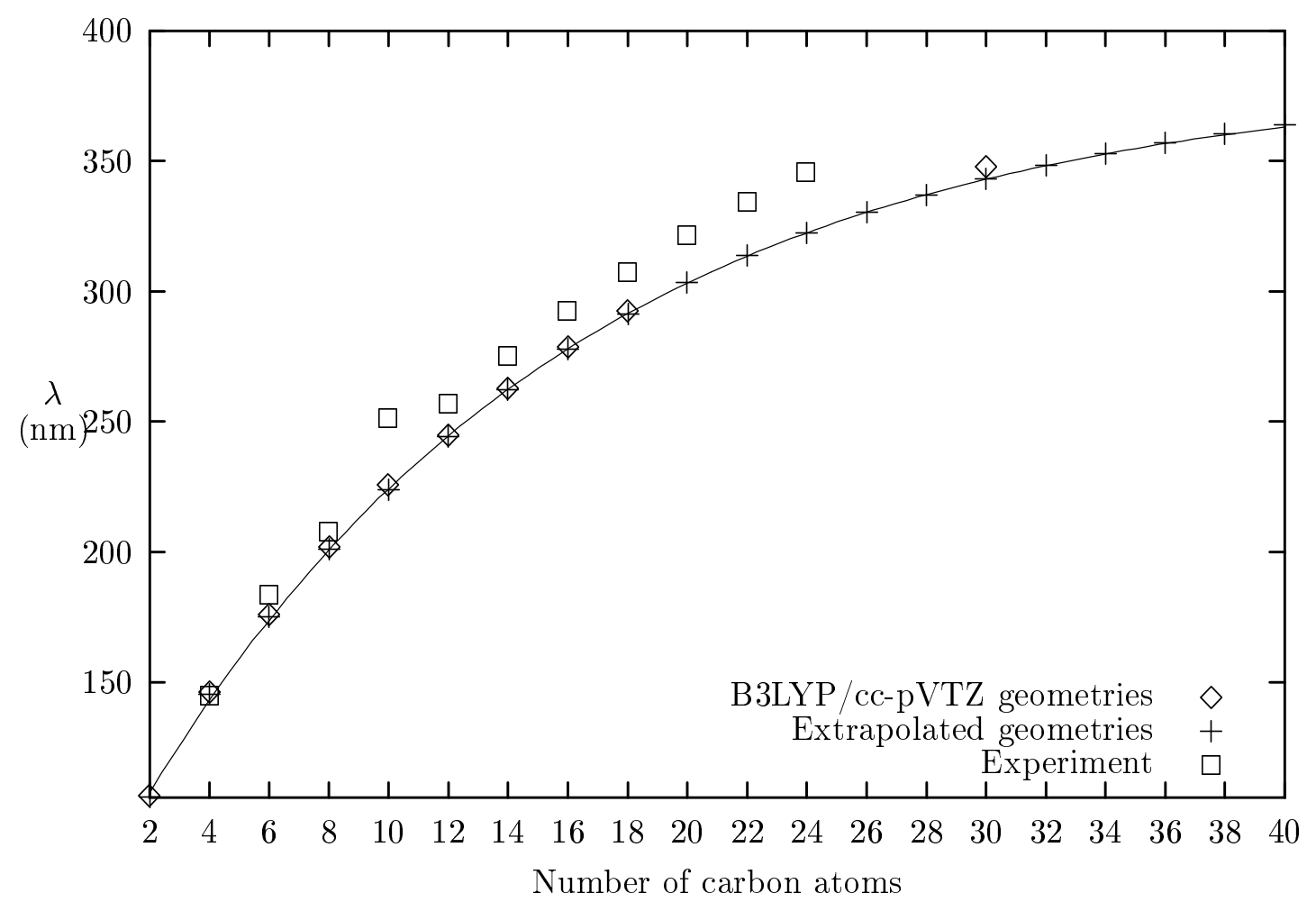

Fig. 1. Wavelength of the first ${ }^{1} \Sigma_{u}^{+} \leftarrow{ }^{1} \Sigma_{g}^{+}$electronic transition in the $\mathrm{HC}_{2 n} \mathrm{H}$ series as a function of the number of carbons in the chain. For more detail on the experimental conditions, see table 2. 


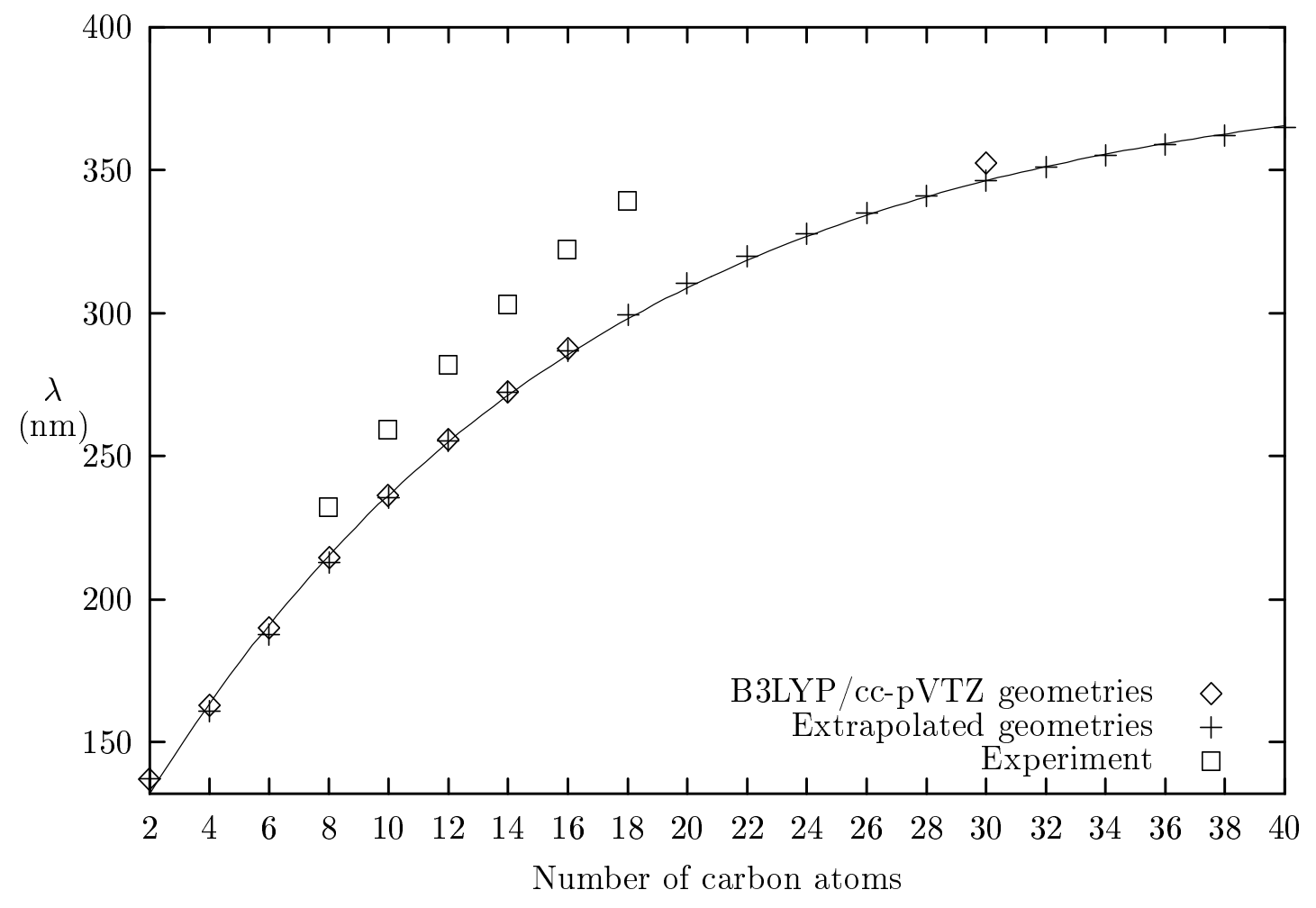

Fig. 2. Wavelength of the first ${ }^{1} \Sigma_{u}^{+} \leftarrow{ }^{1} \Sigma_{g}^{+}$electronic transition in the $\mathrm{NC}_{2 n} \mathrm{~N}$ series as a function of the number of carbons in the chain. For more detail on the experimental conditions, see table 3. 
Table 1

\begin{tabular}{lccc}
\hline & $\lambda_{\text {calc }}$ & $f_{\text {calc }}$ & $\lambda_{\text {exp }}$ \\
\hline \hline $\mathrm{HCN}$ & 113.93 & 0.0334 & 112 \\
$\mathrm{HC}_{3} \mathrm{~N}$ & 145.27 & 1.1129 & 144.9 \\
$\mathrm{HC}_{5} \mathrm{~N}$ & 175.45 & 2.3144 & - \\
$\mathrm{HC}_{7} \mathrm{~N}$ & 202.61 & 3.3196 & - \\
$\mathrm{HC}_{9} \mathrm{~N}$ & 226.14 & 4.3364 & - \\
$\mathrm{HC}_{11} \mathrm{~N}$ & 246.56 & 5.3908 & - \\
$\mathrm{HC}_{13} \mathrm{~N}$ & 264.37 & 6.4641 & - \\
\hline
\end{tabular}

ZINDO wavelengths(nm) and oscillator strengths of the first ${ }^{1} \Sigma^{+} \leftarrow{ }^{1} \Sigma^{+}$transitions in the $\mathrm{HC}_{2 n-1} \mathrm{~N}$ series vs experimental values in the gas phase[24,25]. 
Table 2

\begin{tabular}{lccccc}
\hline & $\lambda_{\text {calc }}^{\mathrm{a}}$ & $f_{\text {calc }}^{\mathrm{a}}$ & $\lambda_{\text {calc }}^{\mathrm{b}}$ & $f_{\text {calc }}^{\mathrm{b}}$ & $\lambda_{\text {exp }}$ \\
\hline \hline $\mathrm{C}_{2} \mathrm{H}_{2}$ & 106.11 & 0.9572 & 105.63 & 0.9466 & - \\
$\mathrm{C}_{4} \mathrm{H}_{2}$ & 145.86 & 2.1436 & 145.00 & 2.0976 & 144.6 \\
$\mathrm{C}_{6} \mathrm{H}_{2}$ & 175.81 & 3.4448 & 174.75 & 3.3860 & 183.1 \\
$\mathrm{C}_{8} \mathrm{H}_{2}$ & 201.73 & 4.6417 & 200.72 & 4.5897 & 207.3 \\
$\mathrm{C}_{10} \mathrm{H}_{2}$ & 225.50 & 5.7458 & 223.73 & 5.7125 & 251.3 \\
$\mathrm{C}_{12} \mathrm{H}_{2}$ & 244.64 & 6.7776 & 244.10 & 6.7575 & 256.6 \\
$\mathrm{C}_{14} \mathrm{H}_{2}$ & 262.48 & 7.7546 & 262.05 & 7.7384 & 274.9 \\
$\mathrm{C}_{16} \mathrm{H}_{2}$ & 278.24 & 8.6878 & 277.75 & 8.6680 & 292.2 \\
$\mathrm{C}_{18} \mathrm{H}_{2}$ & 292.18 & 9.5909 & 291.42 & 9.5604 & 307.3 \\
$\mathrm{C}_{20} \mathrm{H}_{2}$ & - & - & 303.27 & 10.4272 & 321.4 \\
$\mathrm{C}_{22} \mathrm{H}_{2}$ & - & - & 313.55 & 11.2772 & 334.2 \\
$\mathrm{C}_{24} \mathrm{H}_{2}$ & - & - & 322.47 & 12.1169 & 345.4 \\
$\mathrm{C}_{26} \mathrm{H}_{2}$ & - & - & 330.23 & 12.9510 & - \\
$\mathrm{C}_{28} \mathrm{H}_{2}$ & - & - & 336.99 & 13.7817 & - \\
$\mathrm{C}_{30} \mathrm{H}_{2}$ & 347.55 & 14.7146 & 342.91 & 14.6103 & - \\
$\mathrm{C}_{32} \mathrm{H}_{2}$ & - & - & 348.12 & 15.4386 & - \\
$\mathrm{C}_{34} \mathrm{H}_{2}$ & - & - & 352.71 & 16.2662 & - \\
$\mathrm{C}_{36} \mathrm{H}_{2}$ & - & - & 356.78 & 17.0932 & - \\
$\mathrm{C}_{38} \mathrm{H}_{2}$ & - & - & 360.41 & 17.9200 & - \\
$\mathrm{C}_{40} \mathrm{H}_{2}$ & - & - & 363.64 & 18.7458 & - \\
\hline & & & & & \\
\hline
\end{tabular}

ZINDO wavelengths(nm) and oscillator strengths of the first ${ }^{1} \Sigma_{u}^{+}(z) \leftarrow{ }^{1} \Sigma_{g}^{+}$ transitions in the $\mathrm{HC}_{2 n} \mathrm{H}$ series vs experimental values. Experimental conditions : $n=2 \rightarrow 4$ : gas phase[1], $n=5$ : solution[1], $n=6 \rightarrow 12$ : neon matrix[2]. ${ }^{\mathrm{a} u s i n g}$ B3LYP/cc-pVTZ geometries, ${ }^{b}$ using extrapolated geometries. 
Table 3

\begin{tabular}{lccccc}
\hline & $\lambda_{\text {calc }}^{\mathrm{a}}$ & $f_{\text {calc }}^{\mathrm{a}}$ & $\lambda_{\text {calc }}^{\mathrm{b}}$ & $f_{\text {calc }}^{\mathrm{b}}$ & $\lambda_{\text {exp }}$ \\
\hline \hline $\mathrm{C}_{2} \mathrm{~N}_{2}$ & 136.99 & 0.7480 & 137.22 & 0.6423 & - \\
$\mathrm{C}_{4} \mathrm{~N}_{2}$ & 162.66 & 2.6352 & 160.75 & 2.4846 & - \\
$\mathrm{C}_{6} \mathrm{~N}_{2}$ & 189.68 & 4.0674 & 187.68 & 3.9354 & - \\
$\mathrm{C}_{8} \mathrm{~N}_{2}$ & 214.35 & 5.2216 & 212.85 & 5.1357 & 232 \\
$\mathrm{C}_{10} \mathrm{~N}_{2}$ & 236.22 & 6.2624 & 235.30 & 6.2180 & 259 \\
$\mathrm{C}_{12} \mathrm{~N}_{2}$ & 255.55 & 7.2418 & 254.99 & 7.2198 & 282 \\
$\mathrm{C}_{14} \mathrm{~N}_{2}$ & 272.54 & 8.1776 & 272.08 & 8.1609 & 303 \\
$\mathrm{C}_{16} \mathrm{~N}_{2}$ & 287.50 & 9.0854 & 286.82 & 9.0595 & 322 \\
$\mathrm{C}_{18} \mathrm{~N}_{2}$ & - & - & 299.49 & 9.9307 & 339 \\
$\mathrm{C}_{20} \mathrm{~N}_{2}$ & - & - & 310.38 & 10.7860 & - \\
$\mathrm{C}_{22} \mathrm{~N}_{2}$ & - & - & 319.74 & 11.6322 & - \\
$\mathrm{C}_{24} \mathrm{~N}_{2}$ & - & - & 327.83 & 12.4763 & - \\
$\mathrm{C}_{26} \mathrm{~N}_{2}$ & - & - & 334.82 & 13.3190 & - \\
$\mathrm{C}_{28} \mathrm{~N}_{2}$ & - & - & 340.91 & 14.1626 & - \\
$\mathrm{C}_{30} \mathrm{~N}_{2}$ & 352.24 & 15.1285 & 346.23 & 15.0064 & - \\
$\mathrm{C}_{32} \mathrm{~N}_{2}$ & - & - & 350.91 & 15.8524 & - \\
$\mathrm{C}_{34} \mathrm{~N}_{2}$ & - & - & 355.03 & 16.6987 & - \\
$\mathrm{C}_{36} \mathrm{~N}_{2}$ & - & - & 358.68 & 17.5441 & - \\
$\mathrm{C}_{38} \mathrm{~N}_{2}$ & - & - & 361.92 & 18.3902 & - \\
$\mathrm{C}_{40} \mathrm{~N}_{2}$ & - & - & 364.83 & 19.2344 & - \\
\hline & & & & & \\
\hline
\end{tabular}

ZINDO wavelengths(nm) and oscillator strengths of the first ${ }^{1} \Sigma_{u}^{+} \leftarrow{ }^{1} \Sigma_{g}^{+}$transitions in the $\mathrm{NC}_{2 n} \mathrm{~N}$ series vs experimental values measured solution in acetonitrile[22]. ${ }^{\mathrm{a}}$ using B3LYP/cc-pVTZ geometries, ${ }^{\mathrm{b}}$ using extrapolated geometries. 


\section{References}

[1] E. Kloster-Jensen, H.-J. Haink and H. Christen, Helv. Chim. Acta 57, 1731 (1974).

[2] Grutter, M.; Wyss, M.; Fulara, J.; Maier, J. P.; J. Phys. Chem. A 1998; 102, 9785 .

[3] Turner, B.; Astrophys. J. 1971; 163, L35.

[4] Avery, L. W.; Broten, N. W.; MacLeod, J. M.; Oka, T.; Kroto, H. W.; Astrophys. J. 1976; 209, L173.

[5] Kroto, H. W.; Kirby, C.; Walton, D. R. M.; Avery, L. W.; Broten, N. W.; MacLeod, J. M.; Oka, T.; Astrophys. J. 1978; 223, L105.

[6] Arnau, A.; non, I. T.; Silla, E.; Andres, J. M.; E. J. Chem. Ed. 1990; 67, 905.

[7] Pauzat, F.; Ellinger, Y.; Astron. Astrophys. 1989; 216, 305.

[8] MacCarthy, M. C.; Travers, M. J.; Koluras, P.; Gottlieb, C. A.; Thaddeus, P.; Astrophys. J. L125; 467, 1996.

[9] Cernichazo, J.; Guélin, M.; Astron. Astrophys. 1996; 309, L27.

[10] Guélin, M.; Cernichazo, J.; Travers, M. J.; MacCarthy, M. C.; Gottlieb, C. A.; Thaddeus, P.; Ohishi, M.; Saito, S.; Yamamoto, S.; Astron. Astrophys. 1996; 317, L1.

[11] Toublanc, D.; Parisot, J. P.; Brillet, J.; Gautier, D.; Raulin, F.; McKay, C. P.; Icarus 1995; 113, 2.

[12] Gibtner, T.; Hampel, F.; Gisselbrecht, J. P.; Hirsch, A.; Chem. Eur. J. 2002; 82, 408.

[13] Frisch, M. J.; Trucks, G. W.; Schlegel, H. B.; Scuseria, G. E.; Robb, M. A.; Cheeseman, J. R.; Zakrzewski, V. G.; A. Montgomery, Jr., J.; Stratmann, R. E.; Burant, J. C.; Dapprich, S.; Millam, J. M.; Daniels, A. D.; Kudin, K. N.; Strain, M. C.; Farkas, O.; Tomasi, J.; Barone, V.; Cossi, M.; Cammi, R.; Mennucci, B.; Pomelli, C.; Adamo, C.; Clifford, S.; Ochterski, J.; Petersson, G. A.; Ayala, P. Y.; Cui, Q.; Morokuma, K.; Malick, D. K.; Rabuck, A. D.; Raghavachari, K.; Foresman, J. B.; Cioslowski, J.; Ortiz, J. V.; Baboul, A. G.; Stefanov, B. B.; Liu, G.; Liashenko, A.; Piskorz, P.; Komaromi, I.; Gomperts, R.; Martin, R. L.; Fox, D. J.; Keith, T.; Al-Laham, M. A.; Peng, C. Y.; Nanayakkara, A.; Challacombe, M.; Gill, P. M. W.; Johnson, B.; Chen, W.; Wong, M. W.; Andres, J. L.; Gonzalez, C.; Head-Gordon, M.; Replogle, E. S.; Pople, J. A.; Gaussian 98, Revision A.9; Gaussian Inc. and Pittsburgh PA 1998.

[14] M. C. Zerner and J. E. Ridley, Theor. Chim. Acta (Berlin) 1973; 32, 111.

[15] Scemama, A.; Chaquin, P.; Gazeau, M. C.; Bénilan, Y.; J. Phys. Chem. A 2002; in press, available on the web. 
[16] Becke, A. D.; J. Chem. Phys. 1993; $98,5648$.

[17] Lee, C.; Yang, Y.; Parr, R. G.; Phys. Rev. 1988; B37, 785.

[18] Dunning Jr., T. H.; J. Chem. Phys. 1989; 90, 1007.

[19] Moliner, V.; Andrés, J.; Arnau, A.; Silla, E.; Tuñón, I.; Chem. Phys. 1996; 206 , 57.

[20] Hoffmann, R.; Tetrahedron 1966; 22, 521.

[21] Boyd, R. J.; Jones, W. E.; Ling, K. W.; J. Chem. Phys. 1981; 58, 203.

[22] Schermann, G.; Grösser, T.; Hampel, F.; Hisrch, A.; Chem. Eur. J. 1997; 3, 1105.

[23] Ha, T. K.; Nguyen, M. T.; Z. Natürforsch. Teil A 1982; 37, 1272.

[24] G. Herzberg, Molecular Spectra and Molecular Structure. III. Electronic Spectra of Polyatomic Molecules (van Nostrand, Princeton, 1966).

[25] Connors, R. E.; Roebber, J. L.; Weiss, K.; J. Chem. Phys 1974; 60 12, 5011.

[26] Dembinski, R.; Bartik, T.; Bartik, B.; Jaeger, M.; Gladysz, J. A.; J. Am. Chem. Soc. 2000; 122, 810. 